\title{
Ценностно-смысловые характеристики как предикторы созависимого поведения женщин, проживающих с наркозависимым партнером
}

\author{
Анастасия С. Коленова“', Дмитрий А. Гурцкой \\ Донской государственный технический университет, г. Ростов-на-Дону, Российская \\ Федерация \\ *E-mail: kolenova\&nastya@ya.ru
}

\begin{abstract}
Аннотация
Ввеление. В Аанной статье рассматриваются результаты проведенного комплекс-

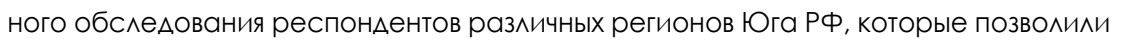
впервые получить Аанные о психологических особенностях проявления созависимого поведения, а также о специфике ценностно-смысловой сореры у молоАых женщин с различной этнической приналлежностью. Новизна исслеАования заключается в разработке психологических моделей созависимого поведения, характерных Аля кажАой вылеленной подгруппы (этнической принаАлежности) с целью Аальнейшей разработки психокоррекционных мероприятий А^я молоАежи, проживающей на Юге РФ.
\end{abstract}

Методы. В исслеАовании было обследовано 330 женщин, проживающих в трех субъектах Юга РФ в возрасте от 17 Ао 30 ^ет, проявляющих различную степень созависимого поведения. Были использованы стандартизированные и проективные метолики, которые предоставили возможность выявить различия в ценностно-смысловой сорере у молодых женщин с различной этнической принаАлежностью, проявляющих созависимое поведение: «Шкала измерения созависимости в отношениях Спанн - Фишер» (адаптация Москаленко), «Тест смысложизненных ориентаций» («PIL» Крамбо и Махолик в модификации Леонтьева), «Методика самоактуализации РОІ Шострома» (модификация Ка^ина), опросник направленности личности (ориентационная анкета) Басса, иМетодика изучения самооценки с помощью процедуры ранжирования» Реана, методика «Ценностные ориентации» Рокича, метолика «Напиши рассказ) (стимульный материал таблиц № 2, 4, 6 «Тематического апперцептивного теста»). Статистические метолы обработки Аанных осуществлялась при помощи пакета компьютерных программ «STATISTICA 10.0».

Результаты. В результате проведенного исследования установлено, что у респонАентов с различной этнической принаАлежностью существуют значимые отличия в характеристике проявления созависимости, как в части Аинамики ситуативной оценки, так и в содержании устойчивых Аичностных конструктов. 
ОБЩАЯ пСИХОлОГИЯ

ОбсужАение результатов. При общих схожих тенАенциях в проявлении созависимости у преАставителей различных этнических групп можно вылелить особенности, отличающие и характеризующие их, что проявляется в межличностном общении с зависимым, с окружением и в принятии себя.

\section{КАючевые слова}

созависимость, созависимые отношения, созависимое поведение, алкогольная зависимость, наркотическая адАикция, интернет-зависимость, смысложизненные ориентации, стратегии поведения, молодежь, этническая принаАлежность

\section{Основные положения}

- этническая приналлежность оказывает влияние на солержание и характеристику созависимых отношений;

- этническая приналлежность оказывает влияние на эфорективность взаимодействия со значимым Аругим, на Аинамику эмоциональных взаимоотношений, ситуативную оценку и устойчивые ^ичностные конструкты (смысловые установки, мичностные ценности и личностные смыслы, устойчивые мотивы Аеятельности);

- психологическая модель, учитывающая особенности мичности в зависимости от этнической группы, направлена на созАание программы психологической коррекции созависимого поведения и ориентирована на изменения ^ичностных смыслов, смысловых установок и повеАенческих конструктов.

\section{Для цитирования}

Коленова А. С., Гурцкой Д. А. Ценностно-смысловые характеристики как предикторы созависимого поведения женщин, проживающих с наркозависимым партнером // Российский психологический журнал. 2019. Т. 16, № 2. С. 43-62. doi: 10.21702/ rpj.2019.2.3

\section{Value-meaning Characteristics as Predictors of Codependent Behaviors in Female Partners of Drug Addicts}

\section{Anastasiya S. Kolenova*, Dmitrii A. Gurtskoi}

Don State Technical University, Rostov-on-Don, Russian Federation

*Corresponding author. E-mail: kolenova\&nastya@ya.ru 


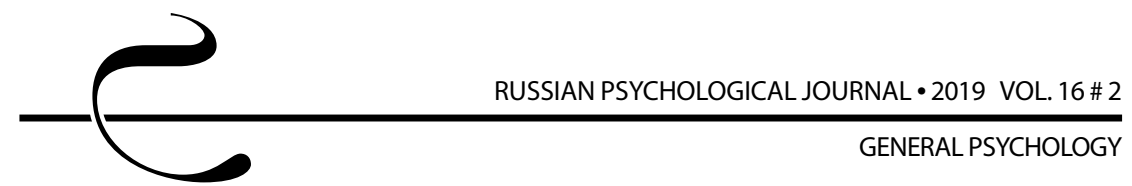

\section{Abstract}

Introduction. This paper discusses the results of a comprehensive survey that involved respondents from various regions of the South of the Russian Federation and represents the first report on psychological characteristics of codependent behavior and valuemeaning sphere in young women of different ethnic groups. The novelty of the study lies in the development of psychological models of codependent behaviors for each ethnic group studied in order to further develop psycho-correction techniques of working with youth in south Russia.

Methods. The sample consisted of 330 respondents with various levels of codependent behaviour residing in three federal subjects of the South of the Russian Federation. The respondents ranged in age from 17 to 30 years. The study used the following standardized and projective techniques to reveal differences in value-meaning sphere among young women of different ethnic groups: (a) the Spann $\square$ Fisher Codependency Scale, SFCDS (modified by Moskalenko), (b) the Purpose-in-Life Test, PIL (developed by Crumbaugh \& Maholic, modified by Leont'ev), (c) the Personal Orientation Inventory, POI (developed by Shostrom, modified by Kalin), (d) the Bass Orientation Inventory, (e) the technique for studying self-assessment using the procedure for ranking (developed by Rean), (f) the Value Orientations technique (developed by Rokich), and (g) the Writea-Story technique (stimulus materials from Tables 2, 4, and 6, Thematic Apperception Test). The STATISTICA, a statistical package software version 10.0, was used for data processing.

Results. The individual participants of different ethnic groups had significant differences in characteristics of codependence, both in terms of the dynamics of situational assessment and in the content of stable personal constructs.

Discussion. Despite of similar trends in manifestations of codependence, the representatives of different ethnic groups are characterized by certain distinguishing characteristics, which manifest themselves in interpersonal communication with addicts and the environment and also in self-acceptance.

\section{Keywords}

codependence, codependent relationships, codependent behavior, alcohol addiction, drug addiction, Internet addiction, meaning-in-life orientations, behavior strategies, youth, ethnic belonging

\section{Highlights}

- Ethnic belonging determines the content and characteristics of codependent relationships.

- Ethnic belonging exerts its effect on the quality of interaction with significant others, the dynamics of emotional relationships, situational assessments, and stable personal constructs, including meaning attitudes, personal values, personal meanings, and stable motives. 
A psychological model which takes into account personality traits depending on the ethnic group helps create a program for psychological correction of codependent behavior and focuses on changes in personal meanings, meaning attitudes, and behavioral constructs.

\section{For citation}

Kolenova, A. S., Gurtskoi, D. A. (2019). Value-meaning Characteristics as Predictors of Codependent Behaviors in Female Partners of Drug Addicts. Rossiiskii psikhologicheskii zhurnal (Russian Psychological Journal), 16(2), 43-62. (in Russ.). doi: 10.21702/rpj.2019.2.3

\section{Введение}

Под созависимым поведением принято понимать выученные поведенческие формы, выражающиеся в самоподавляющем поведении, которое впоследствии приводит к снижению способности инициировать общее участие в различных социальных взаимоотношениях (Fuller \&Warner, 2000; Larsen, 2009).

На данный момент созависимое поведение проявляется в одном из наиболее встречаемых запросов для проведения психокоррекции и психотерапии (Karpman, 2014, Shäfer, Schnack \& Soyka, 2000; Noriega et al., 2008). В связи с этим была предпринята попытка комплексного обследования респондентов различных регионов Юга РФ, что позволило впервые получить данные об особенностях проявления созависимого поведения молодежи в зависимости от их этнической принадлежности (Vasilyuk, 2015; Шамионов и Султаниязова, 2018; Абакумова и Ермаков, 2003).

С точки зрения возникновения созависимости принято выделять 3 фактора: биологический, характеризующий своеобразие реакций для каждого человека на различные раздражители и воздействия (Bornstein, 2006); психологический, включающий в себя личностные психологические особенности, наличие психологических травм в разные возрастные периоды (Beattie, 1989); взаимодействия с другими людьми - как внутрисемейные, так и вне семьи (социальные) (Denning, 2010).

Так, в психологической литературе описаны закономерности контингента, проявляющего созависимые паттерны: обычно это люди, выросшие в семье, где один из родителей был зависим от употребления психоактивных веществ (наркотики, алкоголь); связанные различными отношениями с зависимыми людьми; перенесшие насилие в детском возрасте (физическое, эмоциональное, сексуальное, моральное); выросшие в неполных семьях (Меринов, Шустов и Федотов, 2011).

В современной литературе принято рассматривать феномен «созависимость» как результат адаптации к прошлому опыту. В момент выбора партнера созависимый, порой неосознанно, делает выбор в пользу аддиктивного 


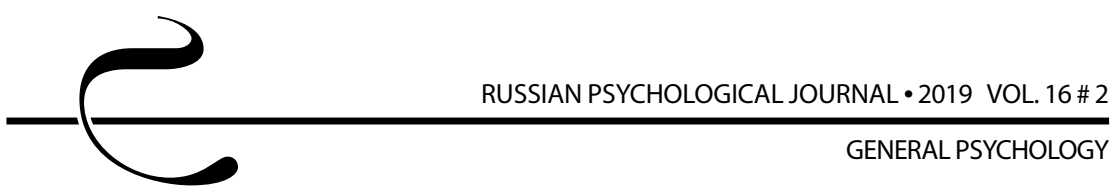

партнера, т. к. видит в нем паттерны поведения, к которым он в свое время научился «успешно» адаптироваться. Оттого, при реабилитации алко- или наркозависимых, наблюдается рецидив, который зачастую провоцирует сам созависимый, хотя он сам и пытается излечить зависимого больного (Wegscheider-Cruse, 1986; Sarkar et al., 2015; Ulusoy \& Guçray, 2017).

Созависимое поведение характеризуется различными психологическими особенностями проявления: сверхконтроль себя и значимого Другого, причем не только поведения, но и чувств и мыслей значимого Другого (Wells et al., 2006; Zetterlind \& Berglund, 1999; Knudson \& Terrell, 2012); суровое отношение к себе и Другим; неконтролируемое желание нравиться другим на фоне неадекватной самооценки; наличие страха критики и острой реакции на нее; неконтролируемое фантазирование и потребность в обмане даже без существенных на то причин; необходимость чувствовать себя «нужным и важным»; непокидаемое чувство вины за себя и Других (Panaghi et al., 2016; McMillen, Zuravin \& Rideout, 1995; Whitfield, 1991).

В структуре личности наблюдается преобладание психологических защит у созависимых: отрицание, рационализация, алекситимия, вытеснение в виде неосознанности своих реактивных действий, а также наличие иллюзии своей незаменимости, отсутствие мотива к саморазвитию (Young, 1987; Абакумова, Мирошниченко и Дмитриев, 2015).

Таким образом, созависимость базируется на особенностях отношений к себе и своим ценностям, т. к. описанные выше психологические признаки связаны с самоотношением, межличностным взаимодействием с Другими, а также с характеристиками ответственности (соотношением принятия и избегания).

Наши представления базируются на том, что при исследовании различных причин поведения личности одним из основополагающих аспектов является характеристика процесса осмысления реальности - его протекание и динамика, что зависит от содержания ценностно-смысловой сферы личности. Ценностно-смысловая сфера формирует ядро личности, представленное в двух компонентах: системе личностных смыслов, отражающих личностные особенности смыслового понимания, а также в личностных ценностях (Бузина и Подосинова, 2010; Леонтьев, 2007). Ценностно-смысловая сфера преобразуется под влиянием социума, но ценностные ориентации отдельных личностей могут оказывать воздействия на коллективные нормы и общегрупповые ценности (Abakumova, Kruteleva \& Ryadinskaya, 2016; Avanesyan et al., 2018).

Яцышин (2003) в этой связи уточняет, что «ценность самого себя, и связанная с ней гармоничная имплицитная теория личности являются одним из важных видов ценностей для каждого человека».

Таким образом, созависимость выступает как определенная трансформация ценностно-смысловой сферы личности, вызванная устойчивыми выученными 
паттернами поведения во взаимодействии со значимыми Другими, опосредующая отношение к себе и все остальные отношения.

Всё это обозначило цель нашего исследования - определить смысложизненные стратегии созависимых представителей молодежи различной этноконфессиональной принадлежности.

\section{Методы}

В исследовании использовались:

1. Теоретический анализ научной литературы.

2. Метод психологического тестирования: тест «Шкала измерения созависимости в отношениях Спанн - Фишер» (адаптация Москаленко); СЖО («Тест смысложизненных ориентаций» («PIL» Крамбо и Махолик в модификации Леонтьева)); методика самоактуализации РОІ Шострома (модификация Калина); опросник направленности личности (ориентационная анкета) Басса; методика «Изучение самооценки с помощью процедуры ранжирования», разработанная Реаном; методика «Ценностные ориентации» Рокича; методика «Напиши рассказ» (стимульный материал таблиц № 2, 4, 6 «Тематического апперцептивного теста» (ТАТ) (Клиническая психометрика: учебное пособие, 2015; Лановой, 2006).

3. Статистические методы обработки данных осуществлялась при помощи пакета компьютерных программ «STATISTICA 10.0».

\section{Выборка}

В исследовании приняли участие 330 человек в возрасте от 17 до 30 лет, проявляющие различную степень созависимого поведения, из Ростовской области (150 человек), Краснодарского края (110 человек) и Ставропольского края (70 человек).

В качестве респондентов были выбраны достаточно многочисленные группы различной этноконфессиональной принадлежности.

\section{Результаты}

Для дальнейшей дифференциации респондентов был использован тест «Шкала измерения созависимости в отношениях Спанн - Фишер» (адаптация Москаленко); нами были получены результаты в 4-х подгруппах (рис. 1):

1) в подгруппе «дагестанцы» признак созависимости у женщин не был выявлен на уровне нормы, при этом больше половины респондентов-женщин попали в группу «ярко выраженная созависимость»;

2) в подгруппе «евреи» незначительное количество женщин (менее 5 \%) попали в категорию «ярко выраженная созависимость»; 


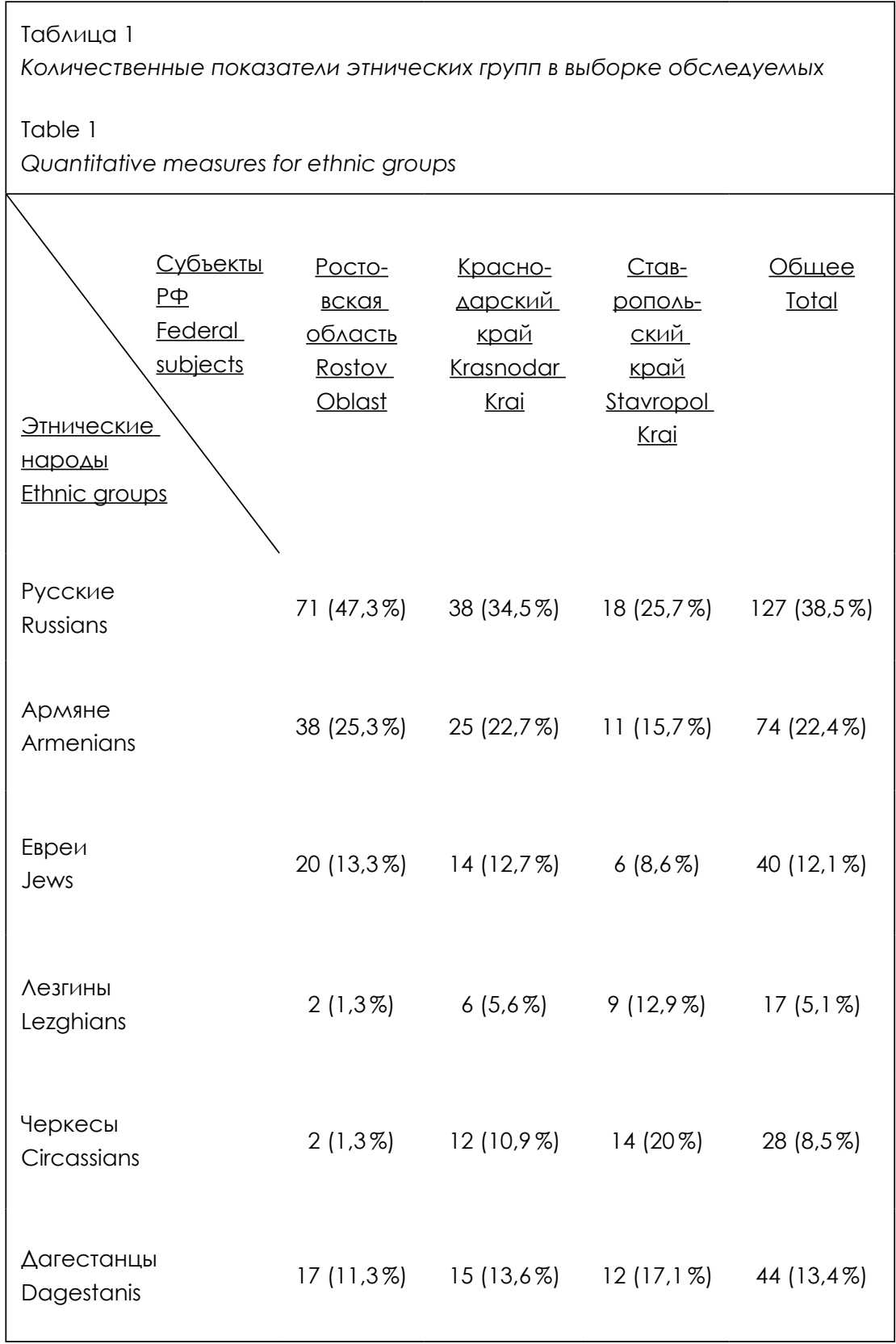




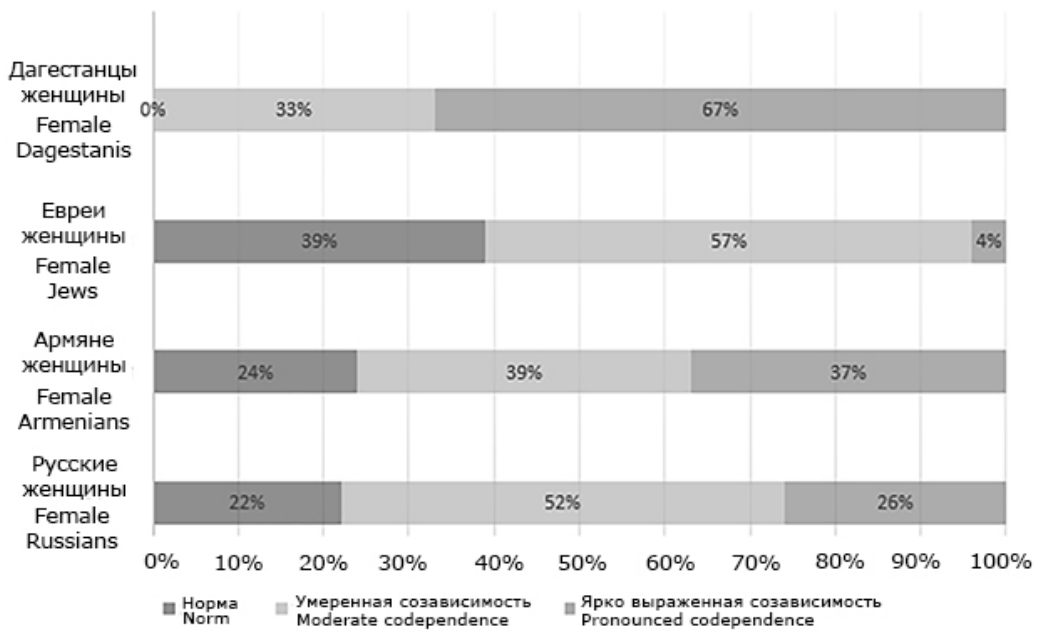

Рисунок 1. Распределение признака созависимости по исследуемым выборкам

Figure 1. Distribution of codependence in the studied samples

3) в подгруппе «армяне» основное число обследуемых проявили умеренный уровень созависимости, но существенно больше проявили ярко выраженную созависимость, чем в подгруппе «евреи»;

4) в подгруппе «русские» подавляющее число обследуемых продемонстрировали средний уровень созависимости - умеренную созависимость.

В исследовании смысложизненных ориентаций обследуемых из разных подгрупп для оценки средних и стандартных отклонений субшкал и общего показателя СЖО (по методике «Тест смысложизненных ориентаций» («PIL» Крамбо и Махолик в модификации Леонтьева)), для выявления различий в характеристиках ценностно-смысловых установок в группах с разной степенью выраженности созависимости был использован Н-критерий Крускала -Уоллиса.

Результаты проверки достоверности различий между респондентами в подгруппе «русские» с различным проявлением созависимости показали, что значимые различия выявлены только по двум параметрам характеристики ценностно-смысловой сферы - «результативность жизни» $(\mathrm{t}=2,584 ; \mathrm{p} \leq 0,05)$ и «локус контроля - Я» $(\mathrm{t}=2,481 ; \mathrm{p} \leq 0,05)$.

Результаты проверки достоверности различий между респондентами в подгруппе «армяне» с различным проявлением созависимости показали, что значимые различия были найдены также по двум параметрам характеристики 
ценностно-смысловой сферы - «результативность жизни» $(\mathrm{t}=2,431 ; \mathrm{p} \leq 0,05)$ и «локус контроля - Я» $(\mathrm{t}=2,417 ; \mathrm{p} \leq 0,05)$.

Таким образом, у респондентов из подгрупп «русские» и «армяне» отличается их оценка результативности жизни, т. е. при разном уровне проявления созависимости испытуемые по-разному оценивают свое включение в жизненные процессы и относятся к своей результативности и оцениванию своих достижений и побед. Также при разной степени проявления созависимости у респондентов подгрупп «русские» и «армяне» отличается ощущение уровня контроля своей жизни и проявления своей воли в этом контроле; испытуемые по-разному оценивают свою ответственность за протекание жизни и ощущение беспомощности в изменении данных процессов.

Результаты проверки достоверности различий между респондентами в подгруппе «евреи» с различным проявлением созависимости показали, что существуют значимые различия по трем параметрам характеристики ценностно-смысловой сферы: «процесс жизни» $(\mathrm{t}=2,311 ; \mathrm{p} \leq 0,05)$, «цели жизни» $(\mathrm{t}=2,229 ; \mathrm{p} \leq 0,05)$ и «локус контроля - Я» $(\mathrm{t}=2,275 ; \mathrm{p} \leq 0,05)$.

Таким образом, показано, что анализируя показатели подгруппы «евреи» по шкале «процесс жизни», респонденты с ярко выраженной созависимостью оказываются неудовлетворенными наполненностью своей жизни. При этом у респондентов с умеренным уровнем созависимости данный показатель снижается, что говорит об относительной наполненности жизни, но при этом не своими интересами и увлечениями, а эмоциями, которые зависят от значимого Другого. По шкале «цели жизни» в группах «норма» и «умеренная созависимость» данный показатель находится в рамках стандартного отклонения от средних значений, при этом в группе «ярко выраженная созависимость» он резко снижается, что свидетельствует о том, что человеку будет присуще, даже при общем высоком уровне осмысленности жизни, поведение живущего только сегодняшним или вчерашним днем. Данные показатели дают право предполагать, что респонденты, которые испытывают созависимость в умеренном виде, транслируют завышенное представление о будущем, ставят огромные планы, но не воплощают их в жизнь. При этом у тех, у которых жизненные цели менее значимы, о партнере отсутствует представление в будущем. «Локус контроля - Я»: баллы по данной шкале указывают на уверенность в своих силах, на возможность и разрешение управлять теми ситуациями, куда попадает человек. Данная шкала иллюстрирует нам прямо пропорциональные тенденции степени проявления созависимости. Таким образом, мы видим, что у тех, кто большей степени проявляет созависимое поведение, степень ощущения собственных сил и возможностей управления собой и своей жизни находится на минимальных значениях или не осознается вовсе. 
ОБЩАЯ ПСИХОЛОГИЯ

Результаты проверки достоверности различий между респондентами в подгруппе «дагестанцы» с различным проявлением созависимости показали, что значимые различия выявлены только в такой характеристике ценностно-смысловой сферы, как «локус контроля-жизнь» ( $=2,387 ; \mathrm{p} \leq 0,05)$. Баллы по данной шкале показали, что наименьшую контроль над своей жизнью испытывают респонденты из групп «умеренная созависимость» и «ярко выраженная созависимость», что указывает на тенденцию респондента из подгруппы «дагестанцы» не брать ответственность за происходящее в жизни.

Таким образом, мы видим, что группы отличаются между собой по статистическим значениям ряда переменных (табл. 2).

\begin{tabular}{|c|c|c|c|c|}
\hline \multicolumn{5}{|c|}{$\begin{array}{l}\text { Таблица } 2 \\
\text { Показатели статистической значимости выявленных переменных } \\
\text { Table } 2 \\
\text { Statistical significance of the studied variables }\end{array}$} \\
\hline Переменные & «Русские» & «Армяне» & «Евреи»» & «Аагестанцы» \\
\hline Variables & $\underline{\text { Russians }}$ & Armenians & $\underline{\text { Jews }}$ & Dagestanis \\
\hline $\begin{array}{l}\text { Результативность } \\
\text { жизни }\end{array}$ & $\dagger=2,584$ & $t=2,431$ & & \\
\hline $\begin{array}{l}\text { Effectiveness of } \\
\text { life }\end{array}$ & $p \leq 0,05$ & $p \leq 0,05$ & & \\
\hline $\begin{array}{l}\text { ^окуС КОНтроля - } \\
\text { я }\end{array}$ & $t=2,481$ & $t=2,417$ & $\dagger=2,275$ & \\
\hline $\begin{array}{l}\text { Internal locus of } \\
\text { control }\end{array}$ & $p \leq 0,05$ & $p \leq 0,05$ & $p \leq 0,05$ & \\
\hline Цель жизни & & & $\dagger=2,229 ;$ & \\
\hline Life purpose & & & $p \leq 0,05$ & \\
\hline Процесс жизни & & & $\dagger=2,311$ & \\
\hline Life process & & & $p \leq 0,05$ & \\
\hline $\begin{array}{l}\text { Аокус контроля- } \\
\text { Жизнь }\end{array}$ & & & & $\dagger=2,387$ \\
\hline $\begin{array}{l}\text { External locus of } \\
\text { control }\end{array}$ & & & & $p \leq 0,05$ \\
\hline
\end{tabular}


Далее было проведено исследование показателей самоактуализации личности с помощью одноименной методики POІ Шострома (модификация Калина). Для определения взаимосвязей между показателями уровня проявления созависимого поведения и критериями самоактуализации был использован коэффициент Пирсона. Было показано, что:

1. В подгруппе «русские» значимые $(p \leq 0,05)$ отрицательные взаимосвязи обнаружились между уровнем проявления созависимого поведения и показателями «шкала компетентности во времени Тс» $(\chi=-0,365)$, «шкала представлений о природе человека Nc» $(\chi=-0,517)$, «шкала синергии Sy» $(\chi=-0,419)$. Данные показатели свидетельствуют о том, что при увеличении уровня проявления созависимого поведения у данной подгруппы респондентов прослеживается ориентация человека лишь на один из отрезков временной шкалы (прошлое, настоящее или будущее) и (или) дискретное восприятие своего жизненного пути; другой человек в целом воспринимается враждебно или негативно, а склонность к целостному восприятию мира и людей, к пониманию связанности противоположностей снижается.

2. Выявлены схожие тенденции в подгруппе «армяне» - значимые $(p \leq 0,05)$ отрицательные взаимосвязи обнаружились между уровнем проявления созависимого поведения и показателями «шкала представлений о природе человека $\mathrm{Nc»}(\chi=-0,414)$, «шкала синергии Sy» $(\chi=-0,453)$. Данные показатели свидетельствуют о том, что при увеличении уровня проявления созависимого поведения у данной подгруппы респондентов восприятие другого человека в целом является враждебным и негативным, а склонность к целостному восприятию мира и других людей снижается.

3. В подгруппе «евреи» при возрастании проявления созависимого поведения были выявлены следующие значимые $(p \leq 0,05)$ корреляционные связи: положительные «шкала ценностных ориентаций Sav» $(\chi=0,333)$ и отрицательные «шкала компетентности во времени Тс» $(\chi=-0,409)$, «шкала представлений о природе человека $\mathrm{Nc»}(\chi=-0,351)$. Таким образом, при возрастании проявления созависимого поведения респонденты данной подгруппы все больше разделяют ценности, присущие самоактуализирующейся личности, но при этом прослеживается ориентация человека лишь на один из отрезков временной шкалы (прошлое, настоящее или будущее), а восприятие другого человека в целом является враждебным и негативным. Возможно, что у этой группы респондентов таким образом проявляется некий компенсаторный механизм.

4. В подгруппе «дагестанцы», так же, как и в подгруппе «армяне», значимые ( $p \leq 0,05)$ отрицательные взаимосвязи обнаружились между уровнем проявления созависимого поведения и показателями «шкала представлений о природе человека Nc» $(\chi=-0,332)$, «шкала синергии Sу» $(\chi=-0,419)$. Данные 
показатели свидетельствуют о том, что при увеличении уровня проявления созависимого поведения у данной подгруппы респондентов восприятие другого человека также носит враждебный и негативный характер, а склонность к целостному восприятию мира и других людей снижается.

Далее было проведено исследование показателей направленности личности (ориентационная анкета Басса). Для определения взаимосвязей между показателями уровня проявления созависимого поведения и характеристики направленности личности был использован $\mathrm{r}_{s}$-коэффициент ранговой корреляции Спирмена. Было показано, что:

1) в подгруппах «армяне» и «евреи» выявлены статистические значимые закономерности $(p \leq 0,05)$ в отношении положительных взаимосвязей между уровнем проявления созависимого поведения и направленностью на себя (Я). Можно предположить, что при возрастании созависимости респонденты склонны к ориентации на прямое вознаграждение и удовлетворение своих потребностей, агрессивны в достижении статуса и власти над Другим, склонны к соперничеству, раздражительности, тревожности, интровертированности;

2) в подгруппах «русские» и «дагестанцы» статистические значимые закономерности не выявлены.

Далее был проанализирован уровень самооценки респондентов по методике «Изучение самооценки с помощью процедуры ранжирования», разработанной Реаном. С помощью линейного коэффициента корреляции Пирсона были показаны следующие закономерности:

- статистически значимые закономерности $(p \leq 0,05)$ были выявлены в отношении подгрупп «русские» и «евреи» $(\chi=0,413$ и $\chi=0,352$ соответственно) - положительная корреляция между уровнем проявления созависимого поведения и ростом уровня самооценки.

При возрастании уровня созависимого поведения у респондентов прослеживается рост от «адекватного уровня» до «завышенного уровня». Также стоит отметить, что в остальных обследуемых подгруппах значимых корреляционных связей не выявлено.

Использование проективной методики «Ценностные ориентации» по Рокичу выявило, что наиболее часто встречаемые терминальные ценности преобладают во всех подгруппах с умеренным и ярко выраженным уровнями проявления созависимого поведения ( $p \leq 0,05)$ :

- здоровье (физическое и психическое);

- уверенность в себе как внутренняя гармония, свобода от внутренних противоречий и сомнений.

Специфичны для подгрупп следующие терминальные признаки:

- красота природы (подгруппа «армяне»); 
- развитие (работа над собой, постоянное физическое и духовное совершенствование) (подгруппы «армяне», «дагестанцы»);

- развлечения (приятное, необременительное времяпрепровождение, отсутствие обязанностей) (подгруппы «армяне», «русские»);

- свобода как самостоятельность и независимость в суждениях и поступках (подгруппы «армяне», «русские»);

- счастье Других (подгруппы «евреи», «дагестанцы»);

- творчество (подгруппа «евреи»).

При этом наиболее часто встречаемые инструментальные ценности преобладают в подгруппах с умеренным и ярко выраженным уровнями проявления созависимого поведения ( $p \leq 0,05)$ :

- ответственность (чувство долга, умение держать слово) (все подгруппы);

- исполнительность, дисциплинированность (подгруппы «евреи», «дагестанцы»);

- аккуратность (чистоплотность), умение содержать в порядке вещи, порядок в делах (подгруппы «армяне», «евреи»);

- непримиримость к недостаткам в себе и других - долженствование (подгруппы «русские», «армяне»);

- самоконтроль (сдержанность, самодисциплина) (подгруппы «русские», «евреи»);

- терпимость (подгруппы «евреи», «дагестанцы»);

- честность (подгруппы «русские», «армяне», «дагестанцы»).

При этом был проведен контент-анализ полученных ответов по методике «Напиши рассказ» (стимульный материал таблиц № 2, 4, 6 «Тематического апперцептивного теста» (ТАТ), отвечающих за тему сексуальных и семейных конфликтов).

Проведенный частотный анализ выраженности шкал в обследуемых подгруппах в изучении направленностей в межличностном взаимодействии, полученный с помощью программы математической статистики $(p \leq 0,05)$, выявил следующие данные:

- преодоление трудностей (22,8 \% подгруппы «русские», 18,4 \% подгруппы «армяне», 14,1 \% подгруппы «евреи», 20,6 \% подгруппы «дагестанцы»);

- отсутствие объектных отношений (5,1% подгруппы «русские», 7,1 \% подгруппы «евреи»);

- слияние (потеря границ) (12,1 \% подгруппы «русские», 21,1% подгруппы «армяне»);

- потребность в одобрении (9,2% подгруппы «русские», 11,7 \% подгруппы «армяне», 10,1 \% подгруппы «дагестанцы»);

- перспектива во времени (8,6 \% подгруппы «русские», 11,7 \% подгруппы «армяне»). 
Таким образом, показано, что все респонденты, имеющие умеренный и ярко выраженный уровни проявления созависимого поведения, при общей возможности оценивать реалистично события вокруг и умении строить функциональные отношения оценивают свою жизнь как осложненную различными испытаниями и трудностями, которые требуют их вовлеченности.

В подгруппах «русские» и «армяне» были выявлены тенденции уступать значимым людям, пренебрегая своими потребностями и находясь в понимании, что надо переждать определенные негативные события, после которых когда-нибудь наступят позитивные изменения, что не дает обследуемым принимать решения в данную минуту.

В подгруппах «русские» и «евреи» были выявлены тенденции: отказа во время взаимодействия видеть потребности других людей, снижения уровня эмпатии и игнорирования отношений с окружающими.

В подгруппах «русские» и «дагестанцы» были выявлены тенденции в наличии потребности в одобрении как ведущего мотива для деятельности.

\section{Обсуждение результатов}

Говоря о проявлении созависимости респондентов различных этнических групп, можно выделить некоторые особенности, отличающие и характеризующие их.

В подгруппе «русские»: чем выше проявляется уровень созависимости, тем выше для них значимости оценки результата деятельности и жизни в целом, тем важнее оценка своих достижений, что приводит к возрастанию необходимости контроля над собой, окружающими и жизнью в общем. При этом сами окружающие люди воспринимаются, в основном, враждебными. Восприятие мира базируется на прошлых воспоминаниях, и общая картина не складывается в представлении созависимого, а лишь обращается внимание на некие значимо важные аспекты. Таким образом, выявлены тенденции компенсаторного механизма у представителей данной подгруппы-желание спасти Другого и видеть в этом свою положительную оценку. Ценными для созависимого человека являются: необременительное времяпрепровождение, отсутствие обязанностей; свобода как самостоятельность и независимость в суждениях и поступках. В тенденциях ориентации и восприятия жизни свойственно: восприятие жизни как необходимости преодолевать трудности; отсутствие границ с другим человеком (всё, что чувствует и испытывает он, я воспринимаю как свое, оценка зависимого - оценка меня); при этом необходимость положительной оценки меня и ожидание, что скоро всё изменится.

В подгруппе «армяне»: чем выше проявляется уровень созависимости, тем выше для них значимость оценки результата деятельности и жизни в целом, тем важнее оценка своих достижений, - что приводит к возрастанию 
необходимости контроля над собой, окружающими и жизнью в общем. При этом сами окружающие люди воспринимаются, в основном, враждебными. Восприятие мира не складывается в общую картинку в представлении созависимого, а лишь обращается внимание на некие значимо важные аспекты. Таким образом, выявлены тенденции компенсаторного механизма у представителей данной подгруппы - перевода внимания на себя. Ценными для созависимого человека являются: работа над собой, постоянное физическое и духовное совершенствование; необременительное времяпрепровождение, отсутствие обязанностей; свобода как самостоятельность и независимость в суждениях и поступках. В тенденциях ориентации и восприятия жизни свойственно: воспринимать жизнь как необходимость преодолевать трудности; отсутствие границ с другим человеком (всё, что чувствует и испытывает он, я воспринимаю как свое, оценка зависимого - оценка меня); при этом необходимость положительной оценки меня; ожидание, что скоро всё изменится.

В подгруппе «евреи» при возрастании уровня созависимости респонденты теряют чувство удовлетворенности наполненностью своей жизни, по-видимому, собственные интересы и увлечения сменяются на необходимость получать эмоции, которые зависят от значимого Другого. Даже при общем высоком уровне осмысленности жизни, при высокой степени проявления созависимости они демонстрируют поведение живущего только сегодняшним или вчерашним днем. Можно предположить, что респонденты, которые испытывают созависимость в умеренном виде, транслируют завышенное представление о будущем, строят большие планы, но не воплощают их в жизнь. Присутствует разделение ценностей, присущее самоактуализирующейся личности (что выступает компенсаторным механизмом у созависимых данной группы), но при этом прослеживается ориентация человека лишь на один из отрезков временной шкалы (прошлое, настоящее или будущее), а восприятие другого человека в целом является враждебным и негативным. При этом, респонденты хотят оказывать помощь зависимому. Ценными для созависимого человека являются счастье Других (детей, старшего поколения), уход в творчество. В тенденциях ориентации и восприятия жизни свойственно воспринимать жизнь как необходимость преодолевать трудности.

В подгруппе «дагестанцы» с возрастанием созависимости наблюдается тенденция не брать ответственность за происходящее в жизни, а перекладывать ее на других людей. При увеличении уровня проявления созависимого поведения у данной подгруппы респондентов восприятие другого человека в целом является враждебным и негативным, а склонность к целостному восприятию мира и других людей снижается. Ценными для созависимого человека являются: работа над собой, постоянное физическое и духовное совершенствование; счастье Других (детей, старшего поколения). В тенденциях 
ориентации и восприятия жизни свойственно воспринимать жизнь как необходимость преодолевать трудности.

\section{Заключение}

Полученные результаты свидетельствуют о том, что существуют различия личностных характеристик созависимых в подгруппах с разной этнической принадлежностью («русские», «армяне», «евреи», «дагестанцы»). Характер распределения степени выраженности созависимости предполагает и качественные различия данного феномена. Интерес представляет и тот факт, что во всей исследуемой выборке уровень проявления созависимости в рамках нормы не представлен вовсе, что требует дополнительного изучения.

\section{Благодарности}

Работа выполнена в рамках гранта РФФИ (проект № 18-013-01209).

\section{Acknowledgments}

Supported by the Russian Foundation for Basic Research grant (project no. 18-013-01209).

\section{Литература}

Абакумова И. В., Ермаков П. Н. О становлении толерантной личности в поликультурном образовании // Вопросы психологии. 2003. № 3. С. 78-82. Абакумова И. В., Мирошниченко А. В., Дмитриев Ю. Ю. Экспресс-диагностика социальной напряженности, агрессивности, враждебности пользователей Интернет в контексте предупреждения и противодействия терроризма // Казанский педагогический журнал. 2015. № 6-3 (113). С. 167-170.

Бузина Т. С., Подосинова Т. В. Ценностно-смысловая сфера женщин, зависимых от алкоголя // Социология власти. 2010. № 2. С. 77-86.

Клиническая психометрика: учебное пособие / под ред. В. А. Солдаткина. Ростов-на-Дону: ГБОУ ВПО «РостГМУ» Минздрава России, 2015. 311 с.

Лановой В. Е. Метод «Напишите рассказ»: диагностика, терапия и прогноз. СПб.: Речь, 2006. 197 с.

Леонтьев Д. А. Психология смысла: Природа, строение и динамика смысловой реальности. М.: Смысл, 2007. 790 с.

Меринов А. В., Шустов Д. И., Федотов И. А. Современные взгляды на феномен созависимого поведения при алкогольной зависимости (обзор литературных данных) // Российский медико-биологический вестник имени академика И. П. Павлова. 2011. Т. 19, № 3. С. 136-141. DOI: 10.17816/ PAVLOVJ20113136-141

Шамионов Р. М., Султаниязова Н. Ж. Ценности и отношение к этнической культуре и традициям как предикторы субъективного благополучия 


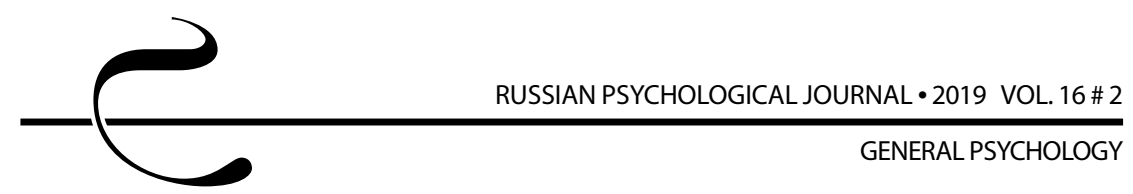

русских и казахов // Российский психологический журнал. 2018. Т. 15, № 1. C. 157-186. DOI: 10.21702/rpj.2018.1.8

Яцышин С. М. Проявление созависимости в ценностно-смысловой сфере матерей при наркотизации ребенка: дисс. ... канд. психол. наук. СПб., 2003. 196 c.

Abakumova I., Kruteleva L., Ryadinskaya E. Transformation of life-sense strategies of a person in the armed conflict environment: Theoretical research // Fullpapers E-Book of 6th World Congress on Psychology and Behavioral Sciences (Management, Psychology, Political and Social Science) (WCPBS 2016). Barcelona, 2016. P. 1-6.

Avanesyan G., Abakumova I., Kruchkova A., Grishina A., Ermakov P. Molecular-genetic correlates of hostile behavior in teenagers and young adults // International Journal of Psychophysiology. 2018. T. 131, Supplement. P. S67. DOI: 10.1016/j. ijpsycho.2018.07.197

Beattie M. Beyond codependency: And getting better all the time. Hazelden Publ., 1989. 256 p.

Bornstein R. F. The complex relationship between dependency and domestic violence: Converging psychological factors and social forces // American Psychologist. 2006. Vol. 61, Issue 6. P. 595-606. DOI: 10.1037/0003-066X.61.6.595

Denning $P$. Harm reduction therapy with families and friends of people with drug problems // Journal Clinical Psychology. 2010. Vol. 66, Issue 2. P. 164-174. DOI: 10.1002/jclp.20671

Fuller J. A., Warner R. M. Family stressors as predictors of codependency // Genetic, Social, and General Psychology Monographs. 2000. Vol. 126 (1). P. 5-22.

Karpman S. A Game Free Life. San Francisco, 2014. 300 p.

Knudson T. M., Terrell H. K. Codependency, perceived interparental conflict, and substance abuse in the family of origin // The American Journal of Family Therapy. 2012. Vol. 40, Issue 3. P. 245-257. DOI: 10.1080/01926187.2011.610725 Larsen E. Stage II Recovery: Life Beyond Addiction. San Francisco: Harper \& Row, 2009. $112 \mathrm{p}$.

McMillen J. C., Zuravin S., Rideout G. Perceived benefit from child sexual abuse // Journal of Consulting and Clinical Psychology. 1995. Vol. 63. P. 1037-1043.

Noriega G., Ramos L., Medina-Mora M.E., Villa A.R. Prevalence of codependence in young women seeking primary health care and associated risk factors. // American Journal of Orthopsychiatry. 2008. Vol. 78, Issue 2. P. 199-210. DOI: 10.1037/0002-9432.78.2.199

Panaghi L., Ahmadabadi Z., Khosravi N., Sadeghi M.S., Madanipour A. Living with Addicted Men and Codependency: The Moderating Effect of Personality Traits // Addict Health. 2016. Vol. 8, Issue 2. P. 98-106. https://www.ncbi.nlm. nih.gov/pmc/articles/PMC5115643 
Sarkar S., Mattoo S. K., Basu D., Gupta J. Codependence in spouses of alcohol and opioid dependent men // International Journal of Culture and Mental Health. 2015. Vol. 8, Issue 1. P. 13-21. DOI: 10.1080/17542863.2013.868502

Shäfer M., Schnack B., Soyka M. Sexual and physical abuse during early childhood or adolescence and later drug addiction // Psychotherapie, Psychosomatik, Medizinische Psychologie. 2000. Vol. 50. P. 38-50.

Ulusoy Y., Guçray S. S. Adaptation of composite codependency scale to Turkish: a validity and reliability study // The Journal of International Social Research. 2017. Vol. 10, Issue 49. P. 373-379.

Vasilyuk F. E. Coexperiencing psychotherapy as a psychotechnical system // Journal of Russian \& East European Psychology. 2015. Vol. 52, Issue 1. P. 1-58. DOI: 10.1080/10610405.2015.1064721

Wegscheider-Cruse S. Choicemaking: For co-dependents, adult children and spirituality seekers. Health Communications, 1986. 217 p.

Wells M. C., Hill M. B., Brack G., Brack C. J., Firestone E. E. Codependency's relationship to defining characteristics in college students // Journal of College Student Psychotherapy. 2006. Vol. 20, Issue 4. P. 71-84.

Young E. Co-alcoholism as a disease: Implications for psychotherapy // Journal of Psychoactive Drugs. 1987. Vol. 19, Issue 3. P. 257-268. DOI: 10.1080/02791072.1987.10472410

Whitfield C. L. Codependence: Healing the Human Condition: The New Paradigm For Helping Professionals And People In Recovery. Health Communications, Deerfield Beach, FL. 1991. 336 p.

Zetterlind U., Berglund $M$. The rate of co-dependence in spouses and relatives of alcoholics on the basis of the Cermak co-dependence scale // Nordic Journal of Psychiatry. 1999. Vol. 53, Issue 2. P. 147-151. DOI: 10.1080/080394899426864

\section{References}

Abakumova, I. V., \& Ermakov, P. N. (2003). On the formation of tolerance in multicultural education. Voprosy psikhologii, 3, 78-82. (in Russ.).

Abakumova, I., Kruteleva, L., \& Ryadinskaya, E. (2016). Transformation of lifesense strategies of a person in the armed conflict environment: Theoretical research. WCPBS 2016. Fullpapers E-Book of 6th World Congress on Psychology and Behavioral Sciences (Management, Psychology, Political and Social Science) (pp. 1-6). Barcelona.

Abakumova, I. V., Miroshnichenko, A. V., \& Dmitriev, Yu. Yu. (2015). Express diagnostics of social tension, aggression, and hostility among Internet users in the context of preventing and combating terrorism. Kazanskii pedagogicheskii zhurnal (Kazan Pedagogical Journal), 6-3(113), 167-170. (in Russ.).

Avanesyan, G., Abakumova, I., Kruchkova, A., Grishina, A., \& Ermakov, P. (2018). 


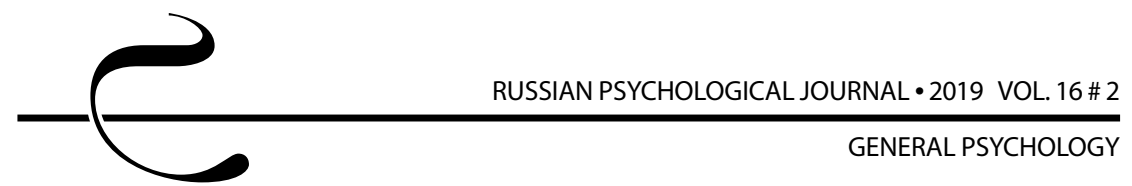

Molecular-genetic correlates of hostile behavior in teenagers and young adults. International Journal of Psychophysiology, 131, Supplement, S67. doi: 10.1016/j.ijpsycho.2018.07.197

Beattie, M. (1989). Beyond codependency: And getting better all the time. Hazelden Publ.

Bornstein, R. F. (2006). The complex relationship between dependency and domestic violence: Converging psychological factors and social forces. American Psychologist, 61(6), 595-606. doi: 10.1037/0003-066X.61.6.595

Buzina, T. S., \& Podosinova, T. V. (2010). Value-meaning sphere of female alcohol users. Sotsiologiya vlasti (Sociology of Power), 2, 77-86. (in Russ.).

Denning, P. (2010). Harm reduction therapy with families and friends of people with drug problems. Journal Clinical Psychology, 66(2), 164-174. doi: $10.1002 /$ jclp.20671

Fuller, J. A., \& Warner, R. M. (2000). Family stressors as predictors of codependency. Genetic, Social, and General Psychology Monographs, 126(1), 5-22.

Karpman, S. A. (2014). Game free life. San Francisco.

Knudson, T. M., \& Terrell, H. K. (2012). Codependency, perceived interparental conflict, and substance abuse in the family of origin. The American Journal of Family Therapy, 40(3), 245-257. doi: 10.1080/01926187.2011.610725

Lanovoi, V. E. (2006). The Write-a-Story technique: Diagnosis, therapy, and prognosis. St. Petersburg: Rech'. (in Russ.).

Larsen, E. (2009). Stage II recovery: Life beyond addiction. San Francisco: Harper \& Row.

Leont'ev, D. A. (2007). Psychology of meaning: Nature, structure, and dynamics of semantic reality. Moscow: Smysl. (in Russ.).

McMillen, J. C., Zuravin, S., \& Rideout, G. (1995). Perceived benefit from child sexual abuse. Journal of Consulting and Clinical Psychology, 63, 1037-1043.

Merinov, A. V., Shustov, D. I., \& Fedotov, I. A. (2011). The modern views of the phenomenon of codependent behavior in alcohol addiction: A literature review. Rossiiskii Mediko-Biologicheskii Vestnik Imeni Akademika I.P. Pavlova (I.P. Pavlov Russian Medical Biological Herald), 19(3), 136-141. doi: $10.17816 /$ PAVLOVJ20113136-141 (in Russ.)

Noriega, G., Ramos, L., Medina-Mora, M.E., \& Villa, A.R. (2008). Prevalence of codependence in young women seeking primary health care and associated risk factors. American Journal of Orthopsychiatry, 78(2), 199-210. doi: 10.1037/0002-9432.78.2.199

Panaghi, L., Ahmadabadi, Z., Khosravi, N., Sadeghi, M. S., \& Madanipour, A. (2016). Living with addicted men and codependency: The moderating effect of personality traits. Addict Health, 8(2), 98-106. Retrieved from https://www. ncbi.nlm.nih.gov/pmc/articles/PMC5115643 
Sarkar, S., Mattoo, S. K., Basu, D., \& Gupta, J. (2015). Codependence in spouses of alcohol and opioid dependent men. International Journal of Culture and Mental Health, 8(1), 13-21. doi: 10.1080/17542863.2013.868502

Shäfer, M., Schnack, B., \& Soyka, M. (2000). Sexual and physical abuse during early childhood or adolescence and later drug addiction. Psychotherapie, Psychosomatik, Medizinische Psychologie, 50, 38-50.

Shamionov, R. M., \& Sultaniyazova, N. Zh. (2018). Values and attitudes towards ethnic culture and traditions as predictors of subjective well-being among Russians and Kazakhs. Rossiiskii psikhologicheskii zhurnal (Russian Psychological Journal), 15(1), 157-186. doi: 10.21702/rpj.2018.1.8 (in Russ.)

Soldatkin, V. A. (Ed.). (2015). Clinical psychometrics. Rostov-on-Don: RostGMU Minzdrava Rossii. (in Russ.).

Ulusoy, Y., \& Guçray, S. S. (2017). Adaptation of composite codependency scale to Turkish: A validity and reliability study. The Journal of International Social Research, 10(49), 373-379.

Vasilyuk, F. E. (2015). Coexperiencing psychotherapy as a psychotechnical system. Journal of Russian \& East European Psychology, 52(1), 1-58. doi: $10.1080 / 10610405.2015 .1064721$

Wegscheider-Cruse, S. (1986). Choicemaking: For co-dependents, adult children and spirituality seekers. Health Communications.

Wells, M. C., Hill, M. B., Brack, G., Brack, C. J., \& Firestone, E. E. (2006). Codependency's relationship to defining characteristics in college students. Journal of College Student Psychotherapy, 20(4), 71-84.

Whitfield, C. L. (1991). Codependence: Healing the human condition: The new paradigm for helping professionals and people in recovery. Health Communications, Deerfield Beach, FL.

Yatsyshin, S. M. (2003). Manifestations of codependence in mothers' value-meaning sphere in narcotization in children (Doctoral dissertation). St. Petersburg. (in Russ.).

Young, E. (1987). Co-alcoholism as a disease: Implications for psychotherapy. Journal of Psychoactive Drugs, 19(3), 257-268. doi: 10.1080/02791072.1987.10472410

Zetterlind, U., \& Berglund, M. (1999). The rate of co-dependence in spouses and relatives of alcoholics on the basis of the Cermak co-dependence scale. Nordic Journal of Psychiatry, 53(2), 147-151. doi: 10.1080/080394899426864 